\title{
Marketing View of Core Competence Cultivating on Business Majors in Private Universities
}

\author{
Huang Dong ${ }^{1}$ \\ ${ }^{1}$ School of Applied Foreign Languages, Zhejiang Yuexiu University, Shaoxing, China \\ Correspondence: Huang Dong, School of Applied Foreign Languages, Zhejiang Yuexiu University, Shaoxing, \\ China.
}

Received: September 27, 2021

Accepted: December 13, $2021 \quad$ Online Published: December 23, 2021

doi:10.5539/ibr.v15n1p110

URL: https://doi.org/10.5539/ibr.v15n1p110

\begin{abstract}
It is necessary and feasible to develop core competencies for busniness majors of private universities. The purpose of this study was to apply business management theories, especially marketing theories to researches on busniness majors, along with the higher education theories.

We trace back core competence theory, point out the essential elements and the interpretations of core competencies on disciplines and majors. It must conform to the law of higher education development, and the interdisciplinary theory should also be taken as an important analysis perspective. Good talents training mode is the key. This paper studies the way to optimize the mode in the perspective of target marketing. We should follow three steps: segmenting, targeting, positioning. We can use multitudinous variables such as age, preferences, interests, etc. to segment education market, employ indifference marketing, differentiated marketing or focus marketing to choose the suitable target market on the basis of our own strengths and weaknesses. And then, offer the tailored talents training plans. Private universities should position themselves properly, it will directly result in school-running ideas, funding, curriculum development, types of talents etc. The training objective is core of training mode, also the cornerstone and guidance of other elements. The curriculum system gives support to achieving training goals, it affects the coordinated development of students' knowledges, abilities, quality structure. The paper uses product theory to inquire into curriculum orientation, curriculum modes and teaching methods. It also expounds the structuring of practical teaching system. School, discipline, and major images intensively embody the core competence, image-building is a process of brand shaping and communicating. Some specific marketing measures are applied to promote business majors development. The measures include internal branding and other three strategies: brand image speaker, affections, cultural charm. Finally, the research conclusions and relevant suggestions are put forward.
\end{abstract}

Keywords: private university, business major, core competence

\section{Introduction}

While the business major is developing vigorously, it also hide the deep crisis. First of all, they are faced with severe competition. In order to compete for limited educational resources, all kinds of educational institutions compete for talented students, excellent teachers, funds, projects and other aspects. In China, there are many universities known as "985 Project", "211 Project", "elite university project", as well as a lot of merged giants. Through the concentration and integration of resources, the gap between private colleges and universities is widening. Besides, many prominent foreign universities are expanding their reach into China (for example, more and more students go to universities abroad for their undergraduate studies), which means that Chinese universities, including private ones, face stronger competitors. Furthermore, many universities recruit students by means of advertising wars, exaggerated publicity and similar pyramid schemes frequently. Lots of homogeneous business majors are set up, which mainly concentrate on hot majors with low investment, leading to a glut of that. And there are many parallel classes from the same major in one college, which eventually leads to the low quality of students' employment. People's demand for higher education has shifted from the pure pursuit of opportunity to the pursuit of quality, the higher education market will be reshuffled. Colleges who lay emphasis on "intensive cultivation" and brand building of majors will have the possibility of survival and development.

Therefore, business majors must cultivate their own core competencies. First, only by cultivating your own core 
competence can we get out of the mud of over competition. And then students would be put in a favorable position in the fierce competition. This paper tries to apply the management theories, methods and technologies, especially the theory of marketing management, to research on cultivating the core competencies of business majors. These theories are mainly applied to the strategic management of for-profit business institutions, their applications in the research of universities will further enrich the theories on the development of business majors. Just as the American educator John Dewey said, in order to develop educational theory, we must apply the principles and methods of other disciplines to educational practice and solve various problems arising in educational practice(Wang Weilian, 2005).

\section{Literature Reviews}

\subsection{About Core Competence}

Core competence is a competitive force formed by enterprises on the basis of long-term accumulation of knowledge and skills, which is adapted to the organizational structure and external environment of enterprises. It is a unique ability formed in the value chain activities to adapt to the market changes and is not easy to be imitated by its rivals. The term core competence was first proposed by Prahalad and Hamel. In the view of them, the concept includes several elements: first, it plays an important role in the operation of the organization, that is, the products or services provided by the enterprise must depend on it; Second, this capability is only available or best used by the organization; Third, it can be superimposed, which means that the relevant core competencies can be reintegrated to form a new and higher level core competence. Fourth, it is not solidified, but in the process of dynamic evolution (Prahalad \& Hamel, 1990).

\subsection{Core Competencies of Disciplines and Majors}

Each major faces special challenges and pressure. In order to avoid being eliminated, it is necessary for all majors to cultivate their own core competencies system. The core competencies of enterprises can be defined as two types: "combination view" and "element view". The core competencies of business majors which transplanted from the business world can also be classified into these two categories. The former refers to the combination of relevant resources, knowledge and ability of business major. The latter emphasizes the most outstanding contribution to the formation of professional competitive advantage from the perspective of core competence (Xu Heqing, 2010).

At present, the research on the core competencies of business majors mainly focuses on the following aspects: firstly, the reform of the training system of "multi-dimensional synergy" in business majors under the background of "new business majors" (Chen Xiaofang, Xia Wenlei et al., 2021); The second is the perspective of curriculum group construction of core competence cultivation for business students under the OBE concept (Zheng Li, 2021); The third is the path and practice of enhancing the core competencies of business students, etc (Wang Ling, 2014).

Recently, growing attention has been paid to the connotation and promotion of core competitiveness of business majors, but the systematic research is not enough. There is still a lack of far-reaching and widely recognized theoretical research. Moreover, the application of theory in practice has just started, and has not achieved significant results, the characteristics and deficiencies are just as follows. First, there are various concepts. The researchers have made a beneficial discussion on the essence and characteristics of the core competitiveness of business majors, and have given their own definitions. But these definitions are not consistent. Second, the analysis of characteristics lacks pertinence. Most of them talk about the core competencies of majors from the perspective of that of enterprises. However, universities are not enterprises after all, and they have their own particularities. Therefore, if the researchers do not consider the mission, function, internal and external environment and operation mechanism from reality, the analyses will be empty and short of pertinence. Third, the cultivation measures are not feasible. Many suggestions have been put forward on how to cultivate the core competencies of business major, such as improving the quality of teachers; building a flat organizational structure; strengthening service consciousness; improving incentive mechanism and so on. While these measures are necessary, there is a lack of further research on how to implement them and make them more workable.

The cultivation of the core competencies must conform to the law of higher education development, and it should also take interdisciplinary theories as an important analytical perspective. This paper will learn more from the relevant marketing principles. The essence of marketing is to create value for customers, which has some congruence with the connotation of core competence. 


\section{Target Marketing}

Target marketing is one of the core theories in the classical marketing system. It consists of three parts: market segmentation, targeting and positioning (STP for short) (Philip Kotler, 2007). It embodies the guiding ideology of "You should know what can be done, and what can not be done". It requires companies to have a deep understanding of consumers and provide personalized products and services for selected market segments, which is essentially a "focus" strategy.

The theory of target marketing is also applicable to universities, especially the private universities which are relatively deficient in resources. Modern university disciplines are so complex and highly differentiated, and even the most prestigious comprehensive universities cannot be proficient in everything. It is impossible for a private university to attract all types of students. It can only choose a few of them to serve according to the university's specialty setting, characteristics and the situation of students. Before that, we ought to divide the prospective freshmen into several groups as mutually exclusive, collectively exhaustive as possible based on some criteria. That called market segments. Then, we will gradually explore and form our own characteristics and advantages, create a number of superior disciplines and majors, and establish our own distinct image in the long-term practice. It dosen't make sense just to pursue a grand scale.

In order to carry out the target marketing effectively, we should complete three main steps: the first step is market segmentation; The second step is to select the target market; The third step is market positioning.

\subsection{Segmentation}

People differ in age, income, preferences, academic interests, geographical distribution and many other characteristics that determine their needs for higher education products.

Demand survey is the first step in the subdivision process. Researchers have informal conversations with students, divide students into undergraduates and high school students who are about to apply for college. The aim is to get a sense of their motivations, attitudes, and behavior patterns. On the basis of the informal survey, they will also issue a formal questionnaire. The questions should include: What factors will affect your choice of college and major when filling in the application? What is the popularity of our major and what do you think of its position among other similar universities? What are your planning for your college career and your expectations for college education? What is the evaluation of different types of universities? We also should know the respondents' demographic variables, psychological variables, and media consumption habits variables (Philip Kotler, 2005).

It is important to emphasize the need for long-term planning when designing the questionnaire. Ideally, the core part of a questionnaire is designed to be reusable, so that after several cycles, we can conduct trend analysis to make some implicit, unambiguous pattern emerge. In fact, the most valuable part of the questionnaire is the data derived from long-term tracking.

The second step of segmentation is the analysis. We can use factor analysis to eliminate redundant variables, and then use cluster analysis to screen out some market segments with the greatest differences.

The third phase is the segmentation. Students are divided into each group with distinctive characteristics according to their different learning objectives, behavior patterns, population variables, psychological variables and so on. We can name each niche group accordingly. For example, we can divide the higher education market into those who pursue a diploma, those who pursue a specific skill, those who pursue a certain interest satisfaction, and those who pursue a higher education experience.

The segmentation criteria in the general marketing theory cannot be completely applied to private higher education. The criteria that can be used are country, region, urban scale in geographical factors; age, gender, nationality and income in demographic factors; social class and character in consumer psychological factors; interests, and loyalty pursued in consumer behavior factors.

In geographical segmentation, for example, the market is divided by region, which can be national, provincial, prefecture-level, or county-level, and students' needs and preferences vary according to where they live. Gender in demographic factors is of research significance for some engineering colleges or foreign language colleges. Generally speaking, the majority of students in engineering colleges are male, while the majority of students in foreign language colleges are female. The income variable and the social class variable have more direct influence on private universities. We need to understand the income and social class distribution of our students, which affects their behavior patterns, their expectations and communication methods. More specifically, it relates to the reasonability of tuition fees, and what kind of financial support system and work-study program the school needs to establish for those less well off students. The variables of pursuing interests let us understand the 
differences in students ' motivation and purpose of learning. It also affect the formulation of talent training programs and how to guide students positively.

\subsection{Select Target Market}

Market segmentation will show some opportunities to schools. Then, private universities would choose among the three categories of market coverage strategies, namely undifferentiated marketing, differentiated marketing and concentrated marketing. Indiscriminate marketing is another name for mass marketing. It's trying to appeal to all types of students and use one talent training plan for all. Differentiated marketing means that school responds to several market segments and provides personalized training programs for each market. Detail at the figure:

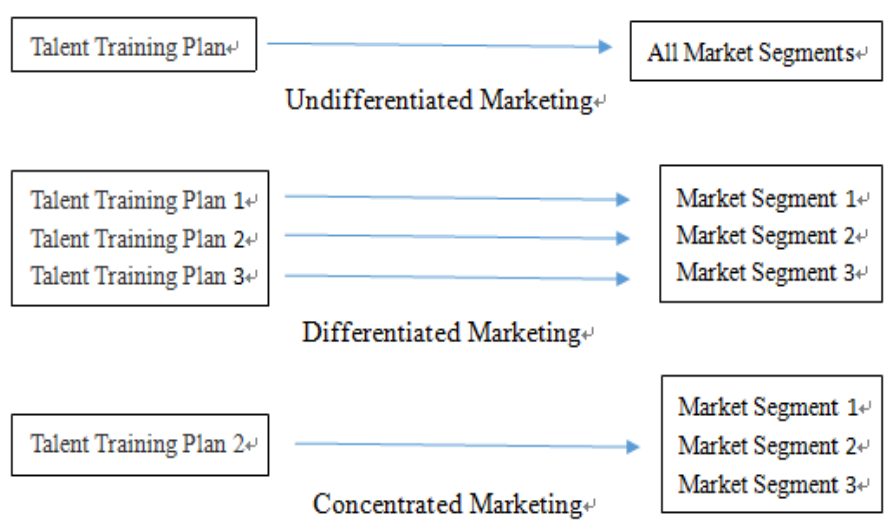

Figure 1. Available market coverage strategies (Philip Kotler, 2005)

Differentiated marketing and concentrated marketing are both options, while undifferentiated marketing is no longer feasible. It's critical to choose the niche market for which we have the most ability to provide services. we call it the core market, that is, the type of students currently attracted by school. The second level of target market is called the desired market. It refers to the students we most hope to attract, but they probably prefer other universities, usually they have strong learning ability or a special talent, and they are also better off financially. The target market of the third level is called a safe market, defined as the school tends to refuse, but is willing to accept if the core and desired market dries up. The fourth tier is the peripheral market, which refers to the type of students whom can be approached and served through special programs, including continuing education and summer training markets. Those are very important work. If done well, they can not only generate income, but also enhance their influences.

\subsection{Positioning of Business Majors}

The meaning of positioning in marketing is "to establish and maintain a distinctive position -- in terms of image and supplies -- so that the institution (or project) occupies a unique and valued position in the mind of consumers in the target market" (Philip Kotler, 2005). Positioning is both an idea and a process. What quality level of students does the school want to serve? Most private universities lack the faculty, curriculum, campus environment and other resources to attract talented students compared with those elite universities. Therefore, it needs to take a pragmatic attitude and realize that a thoughtful and effective university education can significantly increase the "added value" of those students who enter the university with poor academic levels and relevant abilities. And that makes sense. In addition, should private universities be positioned to provide the best course quality or the most thoughtful life service? Is it the most flexible type of education or the cheapest tuition? Is it to focus on the best hardware facilities or to maximize the overall value? Schools should be differentiated positioned, look for niches in the education market, avoid the direct confrontation with the old and prestigious universities, explore and refine their own characteristics, choose a unique brand positioning, and open up a "blue ocean" for their survival and development.

When millions of potential students come to fill out their application form, there are many choices available for them. The natural question to ask is, "Why should I choose this school over others?"

The process of answering this question is a process of positioning. Private universities must consider how they can appeal to their chosen target market and, in particular, how they can stand out from other competitors. Many 
universities are generally pretty good, trustworthy and have good foundation, but they lack distinct characteristics. The purpose of positioning is to make the school hold a unique and valued position in the minds of the target market audiences. If people talk of a specific major of a school, they can immediately associate with some traits, or when there is a need, they immediately think of and only think of the school's major, then the school's positioning is very successful. Because the institution has acquired a certain " uniqueness of category" (Al Ries \& Jack Trout, 2002).

Unique orientation should start from the training of unique students. Private universities must take the road of high-quality and personalized education, and cannot stick to the old three-point teaching mode of "telling-exercise-examination" any more. Individualized education should be the main orientation of private universities. Every student is unique and irreplaceable, we should discern differences, respect differences, and implement different education. Whether in macro curriculum design, or micro curriculum implementation, schools must realize the objective existence of this difference, provide diversified and multi-level courses. There isn't one-size-fits-all criterion. In addition, it is necessary to keep pace with the times and constantly adjust and enrich the characteristics of the school in order to manage the brand image. According to their own endowments and advantages, privately-run schools should devote themselves to keeping their distinct images in the minds of the target public, and cannot simply copy, imitate those famous public schools.

Successful positioning includes three steps:

First, to judge the current image of the school in the eyes of its important public, and how the important public has "positioned" the school. We need to know where we are in order to get to our destination. People often react to the image of a school, not necessarily to its actual condition. If the public have a negative view of a school, they shun or criticize it, and vice versa will be attracted to it. Moreover, people usually build an image of a school in their mind based on limited or even incorrect information that can affect their likelihood of applying for the school, recommending to people around them, and whether to donate or become a member of the school.

To measure the image, first of all, familiarity and likeability should be measured. Each respondent was asked to choose one of the options in the following table

Table 1. Image factor measurement scale

\begin{tabular}{l|l} 
Item & Options \\
\hline Familiarityy & Very Unfamiliar/Relatively Unfamiliar/General/Relatively Familiar/Nery Familiar \\
\hline Likeability & Strongly Dislike/Dislike/Indifference/Like/Strongly Like
\end{tabular}

If the majority of respondents choose the first two or three items, it indicates that the school has a low level of public awareness and serious image problems. We can also take the average of respondents' answers to present them in a more intuitive form, as shown in the figure below:

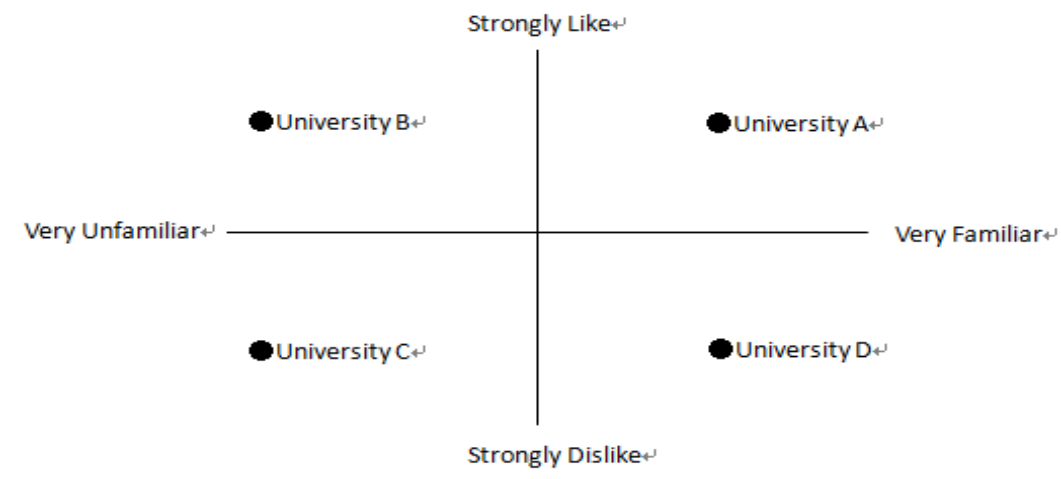

Figure 2. Familiarity - liking analysis of universities (Philip Kotler, 2005)

University A's business major has the best image: most people know it and like it. Although the recognition of University B is not high, people who know it all like it. And C has a negative image in the eyes of those who know it, but fortunately not many people know it. University D is at the bottom of the heap. It's considered a bad university, and everyone knows about it. 
Each school faces a different task. "A" should try to maintain the status quo. "B" must let more candidates and parents pay attention to it, because it has a good reputation foundation. "C" has to work hard to find out why people don't like it and keep its exposure low until its image changes. "D" has to keep a low profile, clean up its act, and start seeking the public's attention again when it becomes a good school.

Second, choose the viable positioning the school wants. Each school needs to further study the elements contained in its image composition, such as teachers, academic level, facilities, school atmosphere, graduates' employment quality, etc., and their positions in the respondents' cognition, so as to facilitate image correction. Decision makers of a private university first have to work out its ideal image, that is, the image they want to build in the mind of the general public.

The ideal image must be practicable under the current situation and resources. Then schools need to decide which gap between the current and ideal image to fill. Decision makers need to consider: how much will the overall image improve if the image differences in a certain dimension are eliminated? What measures need to be taken? What is the cost and time paid? An overall image change plan should consider the priority of the action.

Third, implement appropriate strategies to achieve the desired positioning. Differentiation is a shortcut to achieve the ideal positioning. It's the process of designing a set of meaningful differences that distinguish those of competitors. There are many ways for a school to highlight its differences. For example, by means of the location, the school is located in the capital, commercial center, historical and cultural city, etc.; the size, campus area; the specialized courses; the degree of internationalization; the achievements of graduates, such as the proportion of high-end employment, the proportion of entering a higher school and so on.

\section{Curriculum Design from the Perspective of Product Theory}

\subsection{Selection of Curriculum Outlook}

In modern higher education, the curriculum views mainly include subject centered(knowledge-based), problem centered(society-based), activity centered(student-based) and competence centered (skill-based) (Huang Kexiao, 2005).

From the perspective of modern marketing, it is advisable for private universities to adopt the problem-centered curriculum view and ability-centered curriculum view. Modern marketing concept also brings us enlightenment in this respect. Successful marketing is often problem-oriented, such as big order sales, which doesn't only sell the physical product itself, but also to help solve problems troubling customers, to provide customers with a "solution", to create value for customers and realize their own interests. Problem-centered curriculum view advocates that the curriculum content should be designed around one or more problems, which changes the mode of the subject-centered curriculum view that organizes the curriculum content according to the knowledge logic system. Instead, it separates and recombines the knowledge of multiple related disciplines under the clear problem orientation, reflecting a kind of multidisciplinary intersection. It is easier to cultivate students' ability to analyze and solve practical problems, which is suitable for the training goals of non-academic private universities.

Competence-centered curriculum view attaches importance to the special requirements of employers on vocational ability, advocates the decomposition of vocational activities by job analysis method, so as to determine the key elements to be qualified for a certain position, and then select the corresponding content of the curriculum. Its teaching process and evaluation are based on abilities.

If students regard higher education as consumption of a product, then what is the "core product" of this product? Obviously, it is the way of thinking and learning. It is the "fishing" rather than the "fish". Descartes, in Discourse on Method published in 1637, mentioned that "the most valuable knowledge is the knowledge of methods", which is a widely circulated famous saying.

Since method is so important, it should be a core subject for college students. How can knowledge be integrated? What kind of curriculum do we need? Liu Daoyu, a famous educator in China and former president of Wuhan University, proposed the "four sections with methodology as the main line" curriculum system (Liu Daoyu, 2009), which is a good answer. We can use the overall product concept model in marketing to interpret it, as shown below: 


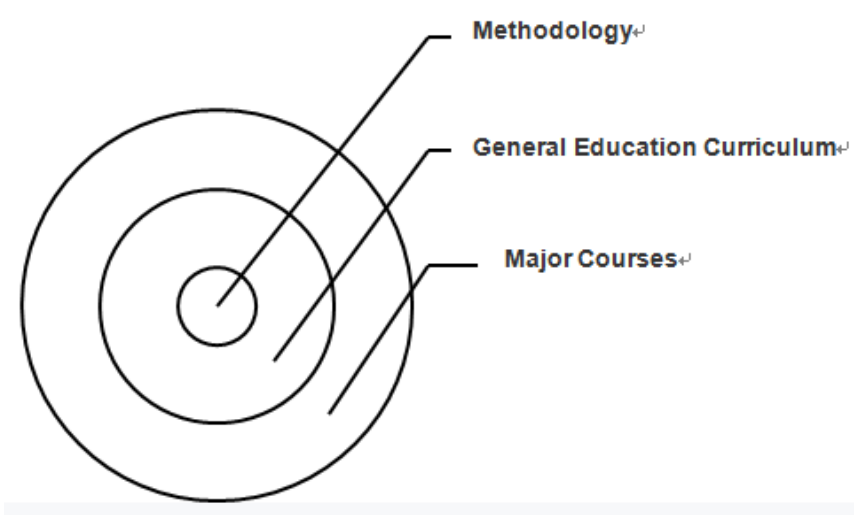

Figure 3. Methodology - oriented curriculum system (Liu Daoyu, 2009)

The curriculum system highlights the importance of methodology. The general education courses in

the picture include basic courses in the humanities and in the natural sciences. They are divided into two types respectively, which are suitable for liberal arts students and science students. In terms of class hours, methodology courses account for 30\%, general courses account for $40 \%$ and professional courses account for $30 \%$. If the methodology course is the "core product", then the general education course is the "actual product", and the professional course is only the "augmented product". This is contrary to the traditional curriculum view which highly emphasizes the importance of professional courses. In fact, it can be understood that, in most cases, professional courses are practice materials by which students exercise scientific thinking ability, master learning methods and obtain self-study ability. It is difficult for students to learn in school specific specialized knowledge that will be used in their future careers, but if they know how to learn in school, they can pick it up quickly when needed in the real world. This is a long-term plan, cultivating such students is the embodiment of the core competencies of universities. There are plenty of examples of outstanding people who end up famous for achievements in areas which is not their primary field of study. For example, Pierre de Fermat, the French mathematician who proposed Fermat's Last Theorem, studied law in college. Leonid Hurwitz, who won the Nobel Prize in economics in 2007 for his theory of mechanism design, is also a law student... In addition to being extremely talented, they are all very good at learning. For business majors, quantitative analysis and written communication ability are important core competencies.

\subsection{Course Mode}

Under the guidance of the subject-centered curriculum view, academic undergraduate universities usually adopt a three-stage curriculum model, which is divided into public basic courses, subject-based courses and professional courses according to the logical order of subject knowledge. The goal of this course mode is to master the subject knowledge systematically and construct a complete theoretical knowledge system, which is suitable for training research-oriented talents. And private universities should adopt the curriculum model of applied undergraduate education.

This model emerged in Europe and the United States in the 1970s, and it is regarded as the applied undergraduate education classics. In Germany, the schools that cultivate applied high-level talents are applied science and technology universities and vocational colleges. Their teaching objectives and curriculum are application-oriented, and they are a mixture of basic education, theoretical research and practice in a certain proportion. Vocational colleges adopt the "dual system" model, that is, students receive vocational skills and professional knowledge training in enterprises, and receive professional theory and cultural knowledge education in schools (Gao Lin, 2006). On the other hand, Australian universities of technology emphasize the combination of students, universities and industry, so that students can not only have certain academic competencies, but also receive practical training for their career. The development of universities cannot be separated from the industry, and that higher education should serve the development of society.

In order to construct the curriculum model of applied undergraduate education, private universities must set up the talent training goal of serving the local or regional economic construction, and the curriculum should be closely related to the social needs. Employers are important customers of university, so it is necessary to emphasize customer orientation, explore the mode of "individualized marketing", and "customize" talents for employers. Compared with public universities, most of private universities in China are positioned to train 
practical or high-skilled talents who are urgently needed to meet social needs. Applied talents should have the ability to solve practical problems on the job site, just like marketing practice of enterprises.

Therefore, it is necessary to analyze the actual work first, decompose it into a number of core work tasks, summarize the basic requirements for talents, including basic quality, knowledge structure, actual operating capacity, core competence and other indicators, and then decide the types of courses required. There are many constraints on curriculum setting in applied education, which makes the curriculum mode diversified and dynamic, and must be adjusted continuously according to the changes of employment market and employers' requirements for talents. One feasible way is to allow senior executives and professional staffs of companies to participate in the talent training in advance, so as to move the staff training forward and implement the so-called "embedded" talent cultivation. Only in this way, the private universities can form a close interactive relationship with the industry, integrate social resources more effectively, and create conditions for implementing the "Dual System" of education.

However, it should be emphasized that applied higher education is not equivalent to simple skills training. The disadvantages of excessive pragmatism in curriculum system are obvious, which may lead to lack of learning ability, lack of development momentum, and limited scope of knowledge. Einstein once pointed out that with too much emphasis on professional education, one can become a useful machine, but not a harmonious person (Einstein, 1979).

In constructing curriculum mode, therefore, we must combine traditional cultural values, humanistic spirits with pragmatism, emphasize quality education and liberal education. To shape students into a qualified citizen, a sane and complete person, with the potential for sustainable development, learning how to learn, getting all-round development. So, the basic subject knowledge cannot be ignored. Although applied undergraduate education is no longer based on the development of discipline, the supporting function of the discipline to the major is irreplaceable. We would not only emphasize professional basic courses, technical ability-knowledge courses, etc., but also pay attention to the discipline basic courses composed of principle knowledge, as well as the general education courses.

School administrators evaluate its curriculum regularly to examine the influence and market adaptability. Some courses and majors play key roles in attracting students, which are called ace courses and majors. A school well known for at least one subject is more likely to attract students and donors, and has positive radiation effects on other majors in the school. Many schools have a "ace major" that they highlight in their brochures. This ace major will help determine and even enhance the quality image of the school.

\subsection{Teaching Method}

Teaching method is restricted by teaching content and is also closely related to teaching objectives. The author thinks that the heuristic teaching method is suitable for students of private universities. It mainly includes problem-based teaching method and case-based teaching method. Problem-based teaching refers to the introduction of problems in the teaching process, so that students can better understand and grasp the knowledge. The case teaching method reflects the guiding significance of marketing research methodology.

The talent training in private universities is characterized by application. In modern universities, a practical teaching form of training applied specialized talents is scientific experiment. The experiments consist of demonstration experiment, verification experiment and design experiment. For most liberal arts majors, presentation and design are more appropriate, ideally by running a real project. However, many practical teaching forms, including study tours, experiments, production practice, etc., can only satisfy a few learners and are suitable for elaborate elite education model. In the mass education model, it is not realistic for most students. In particular, some soft science courses have high requirements on the environment and conditions, mainly because of the scarcity of opportunity resources. Therefore, it is necessary to find a method that can substitute practice to some extent. For the training of business students, case teaching method is a good choice. Case is a kind of connection between theory and practice. To some extent, it can make up for the lack of practice opportunities and partly replace practice, especially suitable for teaching a large number of students.

First introduced as a common teaching method in law, business, medicine, and public policy, case studies are now used in almost all disciplines. When used for teaching purposes, case studies do not need to fully reproduce the actual process of events, instead, they only need to construct a framework for students to discuss and debate. Case studies for teaching need not to consider much about the rigor of the research process, not to quote the original material, nor to require the faithful presentation of empirical data, nor to draw a clear conclusion. In teaching, the case study material is carefully processed to highlight a key point more effectively, which is forbidden in investigative case studies. These features provide greater flexibility and space for case teaching. 
Since Harvard Business School pioneered case teaching methods in 1921, case studies have become a popular model of business administration teaching worldwide. The learning mode from theory to theory is difficult for students to digest and integrate what they learn in time. Case study, however, can provide a sense of scene, a more comprehensive and systematic indirect experience, and help learners to put together a complete picture. The first thing is to determine the source of the case material. Cases based on the writer's direct experience are called direct sources. This requires the author to take part in the practice, that is more convincing when guiding students. Indirect sources are cases that are deliberately collected and compiled. Undoubtedly, people with practical experience are more likely to write good case works.

Teachers should give full play to the role of organizers in case teaching. Encourage and guide students to conduct divergent thinking, inspire each other among the group members, and draw appropriate conclusions. In this process, the status and role of teachers are different from those in the teaching of theoretical courses. Obviously, the main task is changed from theoretical knowledge teaching to guiding students to think independently. To sum up, the main role of teachers is to guide and inspire students, and then to coordinate and generalize. At the same time, teachers should encourage students to hold different opinions on questions and avoid simply publishing the "standard answers".

We do not want to abandon the standard practical teaching forms such as tutor system and production practice. In fact, people with real practical experience will have a deeper understanding of the case studies. But we cannot be confined to standard practice. Case study and teaching should be strengthened, and theoretical teaching should not be neglected. Theoretical teaching is the premise and foundation of case teaching, and case study is the deepening and extension of theoretical teaching.

\section{Brand Marketing Measures to Promote Business Majors}

\subsection{Internal Branding}

Internal branding is a process that helps employees understand the brand and is positively motivated by it. It is also a process in which the overall brand advantages of the university are being reflected in various elements of the organization, such as teachers, students, staff, departments, majors and societies. The public will naturally associate an internal brand with its school, and the relationship is mutually beneficial. For example, there is a high-level major or subject in a school, and when people mention it, they think of the school simultaneously. Every faculty member in the school should become a practitioner of the brand, and only when they care about and believe in the brand will they be motivated to work harder and be more energetic. One of the challenges for private universities to attract and retain talents is how to enhance the sense of belonging of staff. It's critical to enhance employees' sense of identity and improve financial treatment.

\subsection{Three Strategies}

\subsubsection{Brand Spokesman}

It refers to the training of luminaries in universities, Outstanding alumni endorsement will have a strong impact on the public. A large number of average students who are not the best but are quite good, and who are satisfied with their school and their progress, are also very important advertising and may be more realistic. According to the principle of word of mouth marketing, there are about 250 hidden customers behind every current customer. This description of retail can't be applied simply to school word of mouth, but the enlightenment it brings is true. If the business majors of private universities can be properly positioned, and the advantageous resources can be concentrated, it is completely possible to cultivate some excellent students who have academic success and career success, and they will become the most convincing image spokesmen of the school. We should attach importance to the construction of the alumni association, assign special personnel to be responsible for the daily management and operation, make full use of alumni resources, and form a strong external network.

\subsubsection{Retaining Talents Through Sentiment}

In order to reduce the high turnover rate of teachers, many private universities develop some strategies such as "better pay and better conditions", "feelings of brotherhood", "career advancement opportunities", etc. and implement them to some degree. However, the turnover rate of teachers is still too high due to the institutional reasons of private universities and the gap of the political status, social status and economic treatment compared to teachers in public universities, as well as the feelings of uncertainty and competitive pressure. There is a problem in the orientation of the relationship between schools and teachers, that is, school administrators are regarded as hosts and teachers as guests. The key is to let teachers become masters, to consider teachers as the most important and valuable assets of schools, and to abandon the "tool view" of teachers in school operation. We should link the improvement of teachers' pay with the evaluation mechanism, formulate a 
workable staff manual, focus on strengthening the management of teachers, carry out effective assessment, and set up a series of innovative personnel incentive awards such as "the most popular teacher" title, "teaching quality award", "teaching paper award", "distinguished teacher award", "talent introduction award", "good suggestion award", "special contribution award" and so on. Award "housing fund", "car purchase fund" etc. to outstanding faculty members. Let every teacher have senses of crisis, honor, achievement and belonging.

\subsubsection{Culture}

Although universities are places where knowledge is created and disseminated, they do not necessarily have culture. University culture is a relatively fixed group psychological mode and behavior mode formed in the long course of development. It is an important factor affecting people's social welfare and production efficiency. It not only promotes production, but also has an important impact on innovation (Yan Chengliang, 2012). Culture is also a kind of social capital that refers to the characteristics of social organizations, such as trust, norms, networks, etc., which enhance social effectiveness by facilitating coordinated action. For private universities, it refers to the obtaining of social resources beneficial to the school through the interpersonal network built by alumni, principals, teachers, investors, etc.

\section{Conclusions and Suggestions}

This paper studies the cultivation of core competencies of business majors in private universities. We probe into the characteristics and driving factors of developing the core competencies, and discuss the strategies of making it.

The main conclusions of this study are as follows:

First, talent training mode is the key element of cultivating core competence. This paper explores how to optimize talent training mode from the perspective of marketing management, demonstrates the necessity, feasibility and significance of implementing target marketing for business majors in private universities. We analyze how to segment the market, choose the target market and positioning. Private universities should jointly adopt various variables such as students' intelligence quotient, academic interests, financial conditions, geographical distribution and other interests they pursue to segment the educational market. And according to their own conditions, employ differentiated marketing or centralized marketing to choose the students who have high level of identification with school as the target market. Then, position themselves to pursue the "uniqueness of the class" as the goal, establish a unique, distinct image.

Second, use brand marketing to analyze development strategies of business majors for the purpose of cultivating core competencies, and specifically implement internal branding and three strategies, namely brand spokesman strategy, sentiment strategy and culture strategy.

Third, the core competencies of business majors are also deeply influenced by the quality of teachers, students and staff, evaluation and incentive mechanisms, campus environment, professional practices, the achievements of alumni and other factors.

The main suggestions include:

First, to build a talent training plan different from that of public universities, and train talents in a more pragmatic orientation (Xu Xuqing, 2012). For example, the theoretical knowledge is moderate and just enough, puts more emphasis on practical ability and social adaptability.

Second, draw lessons from the applied undergraduate education curriculum model, so that students can not only have certain academic ability, but also receive practical training for career, they must complete practical teaching with learning by doing. And private universities can form close interaction with the industry. Design curriculum guided by problem-centered and competence-centered principle.

Third, use heuristic teaching method, including problem-based teaching method and case teaching method. It is helpful for students to gain indirect experience, especially in the case of teaching a large number of students, and is more conducive to achieving the goal of talent cultivation.

Finally, build school brand and attach importance to communication. Use integrated marketing communication to ensure "unified image, unified voice and unified discourse", to fulfill tasks such as identification of target audience, information spreading, media selection, feedback collection and so on, use a variety of online, offline, traditional and new media, practice all-participated public relations.

\section{Acknowledgements}

This research is supported by Planning Project of Education Science of Shaoxing City, "Research on the core competence of private universities from marketing perspective" (grant number SGJ16040). 


\section{References}

Al Ries, J. T. (2002). Positioning. Beijing: China Financial and Economic Press (pp. 5-10).

Chen, X. F., \& Xia, W. L. et al. (2021). The Connotation of New Business in the New Era and the Reform of "Multi-dimensional Coordination" Training System. Finance and Accounting Monthly (pp. 107-113).

Einstein. Einstein Collection. Beijing: The Commercial Press (pp. 310).

Gao, L. (2006). Introduction to Applied Undergraduate Education. Beijing: Science Press (pp. 67).

Huang, K. X. (2005). On the Establishment of Technical Undergraduate Education Curriculum System. Journal of Shanghai Institute of Electrical Engineering (pp. 12).

Liu, D. Y. (2009). Creation: The Soul of First-class University. Wuhan: Wuhan University Press (pp. 212-215).

Philip, K. (2005). Strategic Marketing of Educational Institutions (2nd edition). Beijing: Enterprise Management Press (pp. 196-215).

Philip, K. (2007). Kotler Marketing Strategy. Beijing: CITIC Press.

Prahalad, C. K., \& Gary, H. (1990, May-June). The Core Competence of the Corporation. Havard Buisness Review (pp. 79-90).

Wang, L. (2014). The Path and Practice of Improving the Core Competitiveness of Higher Vocational Business Students. Education and Career (pp. 178-179).

Wang, W. L. (2005). Research on The Operation Mechanism of Chinese University Teaching. Guangzhou: Guangdong Higher Education Press.

Xu, H. Q. (2010). Research on The Core Competitiveness of Universities from the Perspective of Enterprises. Hangzhou: Zhejiang Gongshang University Press.

Xu, X. Q. (2012). Research on Internal Management System Reform and Innovation of Private Universities in China. Beijing: China Social Sciences Press (pp. 142-172).

Yan, C. L. (2012). Social Capital, Innovation and Long-term Economic Growth. Economic Research Journal (pp. 59).

Zheng, L. (2021). Study on Curriculum Group Construction of Business Students' Professional Core Competence Cultivation under the Concept of OBE. Heilongjiang Education (pp. 26-30).

\section{Copyrights}

Copyright for this article is retained by the author(s), with first publication rights granted to the journal.

This is an open-access article distributed under the terms and conditions of the Creative Commons Attribution license (http://creativecommons.org/licenses/by/4.0/). 